\title{
Experimental study of the honeycomb composite material under high velocity impact
}

\author{
Luay Hashem Abbud ${ }^{1}$, Essam Zuheir Fadhel ${ }^{2}$, Murtadha M. Mottar Al-Masoudy ${ }^{3}$ \\ ${ }^{1}$ Department of air conditioning and refrigeration, Technical Engineering, AL - Mustaqbal university college \\ 2 Department of Mechanical Engineering, University of Babylon \\ ${ }^{3}$ Department of air conditioning and refrigeration Technical Engineering, AL - Mustaqbal university college
}

\begin{abstract}
This study deals with the effect of complex material made from (Kevlar29, Honeycomb Aluminium and Carbon fibers) under high velocity is measured, also this material tested to specify the mechanical properties, then the high-impact loading utilizing the energy absorption tests were performed experimentally by using a gas gun device with shape of impactors flat cylindrical bullets. The discussion of the results of this work was termed under the failure of the coupling mode of the projectiles. The velocity level and defamatory affect the kinetic energy of the projectile. The thickness of the target has an impact on the projectile speed.
\end{abstract}

The findings are discussed in terms of the work done to link the failure modes with the kinetic energy fall of the projectile and its effect on ballistic maximum velocity. The effect on the rate of the target thickness was then addressed. The vitality assimilation was anticipated by expecting that all out work done in the disfigurement of the plates is comparable to the total loss of the motor vitality of the shot. The connection between possible speed and the thickness of composite material was perceived. The hypothetical outcomes demonstrated great understanding contrasted and the test work.

\begin{tabular}{ll}
\hline Keywords: & $\begin{array}{l}\text { Honeycomb Aluminum; High Velocity Impact; Ballistic Velocity; Composite } \\
\text { Materials }\end{array}$ \\
\hline
\end{tabular}

\section{Corresponding Author:}

Luay Hashem Abbud

Lecturer Department of air conditioning and refrigeration Technical Engineering

AL - Mustaqbal university college, Babylon, Iraq

E-mail: luayhashem@yahoo.com

\section{Introduction}

Several industries use honeycomb panels, because of their lightweight, high strength and light power consumption. Airplane industries often use honeycomb panels. The inner and outer body of a plane has been studied as of late Alavi et.al [1], which made of honeycomb and sandwiches under dynamic semi-static loading.

Essam [2] On the other hand, aluminum alloys have long been preferred for civil and military aircraft due to their having high strength/weight ratio (lightweight), excellent weldability, the low value of thermal expansion coefficient and excellent corrosion and abrasion resistance. Therefore, these properties of aluminum alloy attribute the rapid increase of using this alloy in automotive structural applications Essam [3].

The high-velocity impact produces a short duration, steeply rising loading pulse when impacting the structure. Due to a high strain frequency, it is regulated by electromagnetic factors, force transmission, and increases in structural rigidity, intensity, and fracturing strength. While such damage decreases the structure's load-bearing strength, its consequences can usually be predicted using the principles of fracture mechanics. At higher velocity, the mechanical object's reaction is controlled by the ma's specific actions., Enock et. al [4]. Abbud [5] introduced a new theoretical prediction model to fracture properties of dual-layered translucent plastic products whereby aluminum and compact steel conical tip bullets get an effect acceleration rate of 100-970 m / s. The energy has been assumed to become the loss of the velocity vector energy and also to be categorized into three forms that contain the work was bendable and it was petalled and the sandwich was achieved. They 
noted that perhaps the polymer objectives had shown their distinctive shape of inability comparable to the shape of inability which is identical to what has been recorded for dual-layer thin steel objectives.

Moreover, The fracture capacity in the power series feature is observed to increase with the target thickness.

Also, [ 6 ] explored a reaction of modified polymer chipboard molded fiber Kevlar29-Al2O3 Powder/ Epoxy confined to high-velocity impact load. The results showed the highest possible hypersonic maximum at effect velocity was figured to be $390.87 \pm 6 \mathrm{~m} / \mathrm{s}$ for the $18 \mathrm{~mm}$ specified density. The key findings that, as the event velocity decreases past the ballistic maximum velocity, delamination and high deformation energies have been shown to be raised. Additionally, it has been found that only the absorbed energy subject to effect is lower for a hybrid polymer that has the higher material properties that were the improvement in target thickness increases a target's kinetic quality.

Where [7] Described the malfunction types related to high-speed glass, bi-methyl-methacrylate and polycarbonate firing aim for high-speed circular metal bullets in the distance from $100 \mathrm{~m} / \mathrm{s}$ to $950 \mathrm{~m} / \mathrm{s}$. The objectives of carbon fiber showed very similar patterns of failure to those demonstrated medium-thick ductile metallic targets. The glass and the polymethyl-methacr, however,

The glass and poly-methyl-methacrylate objectives have always been totally different in appearance. Under high-speed impact, Glass demonstrates the lowest behaviour. The targets of poly-methyl-methacrylate are discovered to perform poorly mainly across the crack structure. three products examined, polycarbonate was observed to be much more appropriate to overcome high-speed influence and preserve protection at the same time.

The overall aim of this research is to study the response of new composite materials (Honeycomb Aluminium, Kevlar29 and Carbon fibers) and these were tested to specify the mechanical properties, then the high-impact loading utilizing the energy absorption tests were executed experimentally by using a gas gun device with the shape of impactors flat cylindrical bullets.

\section{Experimental setup}

The high-speed effect machine powered by the gun uses composted gasses as in its kinetic energy. The gun basically uses the motion principle of Newton to represent the acceleration of the shot in the tube, using helium as a working gas. As shown in Figure (1), it consists of the pressure tank unit, the terminating instrument unit, the beginning unit, the capture chamber and the approximate speed.

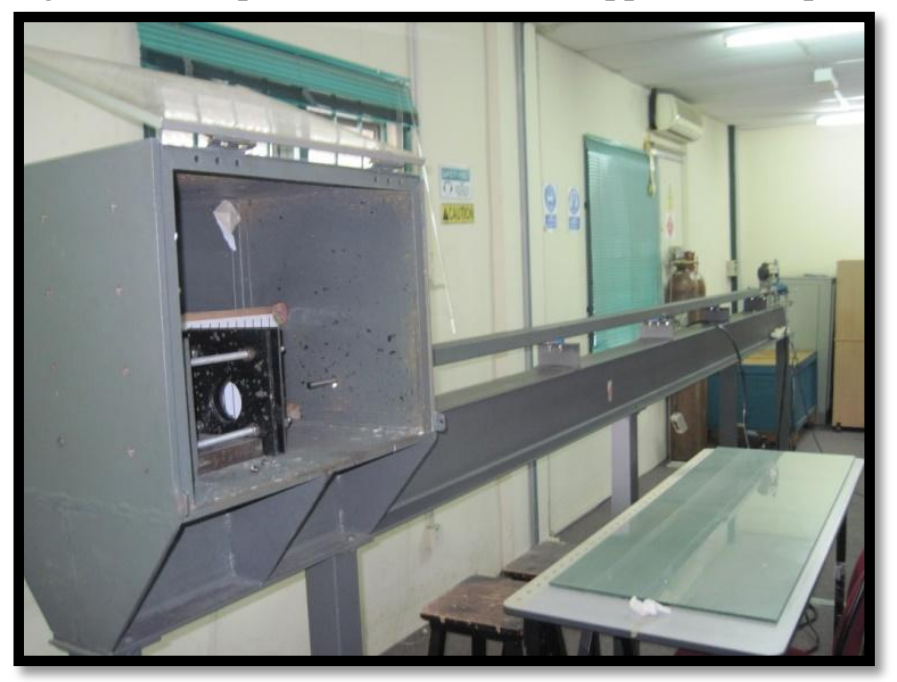

Figure 1. Ballistic panel gas gun.

The gun is anticipated to have the ability to dispatch a shot with a nuzzle speed (i.e. shot release) of below 500 $\mathrm{m} / \mathrm{s}$ At 3000 psi supply tank pressure. The higher speed is possible if the projectile is heavier and the tank pressure is maximum. The pressure tank unit involves a round and hollow gas tank, the pressure controller pressure vessel and pressure control valves shown in Figure (2).

The reservoir tank was designed from high strength steel and carefully machined to undertake the high operating pressure. The vessel cap or end cover has been secured using hardened and oil- quenched bolts for better safety. A pressure control valve will be used as an opening for the intake of gas into the vessel while the 
pressure regulator is used to regulate the reservoir pressure. Since the conventional valve influences the firing performance of the gun, it is carefully selected. An electrically-controlled valve or pneumatic actuator has been chosen to provide fast triggering as it can also perform under continuous high-pressure operations.

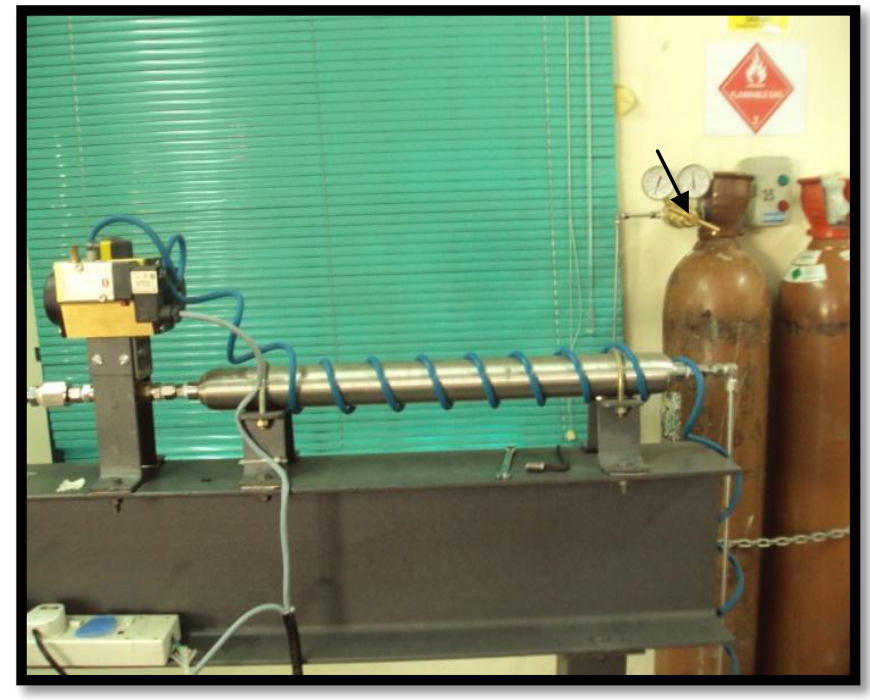

Figure 2. Pressure reservoir unit consisting of a cylindrical gas tank, pressure regulator, pressure vessel and pressure control valves.

The gun barrel has been constructed as a long cylindrical tube that means that the bullet passes through and fires at the targets. The barrel has been machined with a flat interior surface to minimize friction between the projectiles. There are two parts of the barrel, which are the loading mechanism at one end for projectile loading and the propellant mechanism at the other end for shooting purposes. The breach will be connected to the solenoid valve with a complete firing mechanism and a collar sleeve was designed to close the launching unit once the projectile has been placed into it. The other end of the gun barrel is the catch chamber. The catch chamber provides room for holding the specimen to be tested (targets). A small window has been designed at both sides of the catch chamber for visual viewing.

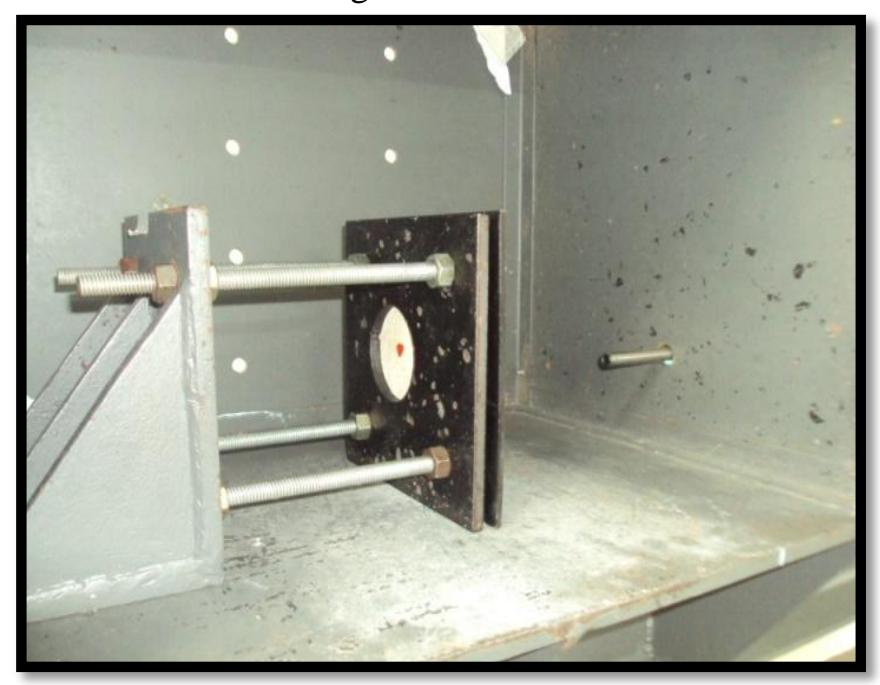

Figure 2. The target sample between the base and the anvil was positioned

\section{Test specimens preparation}

Hand exposes up is a contact forming in uneven molds is the least expensive and most normal procedures for making composite items. This method is the most common choice in the aircraft industry in the United States, Australia, Europe and Asia. The tool for the lay-up process was prepared such as bolt roller, roller brush, scissor, rubber glove, apron, goggle and respirator at the table a side of the glass mold. The other side was prepared the kitting materials. 
The safety precaution needs to be aware when performing the lay-up process because of the fume or smell of the hazardous chemical and the chemical itself Nagendra et. al [8]. After the resin mixed, the lay-up started with the resin was applied at the glass by using the roller brush Figure (4) before placing the kevlar cloth and wet it off. Then, the roller bolt was used for removing the void. Then the carbon was applied for two layers. Then, the carbon veil was applied before placed the honeycomb as the core and the next face is symmetrical Figure 5. Bolt roller needs to be applied for every layered before placed a new layered for removing the void Guynn et. al [9].

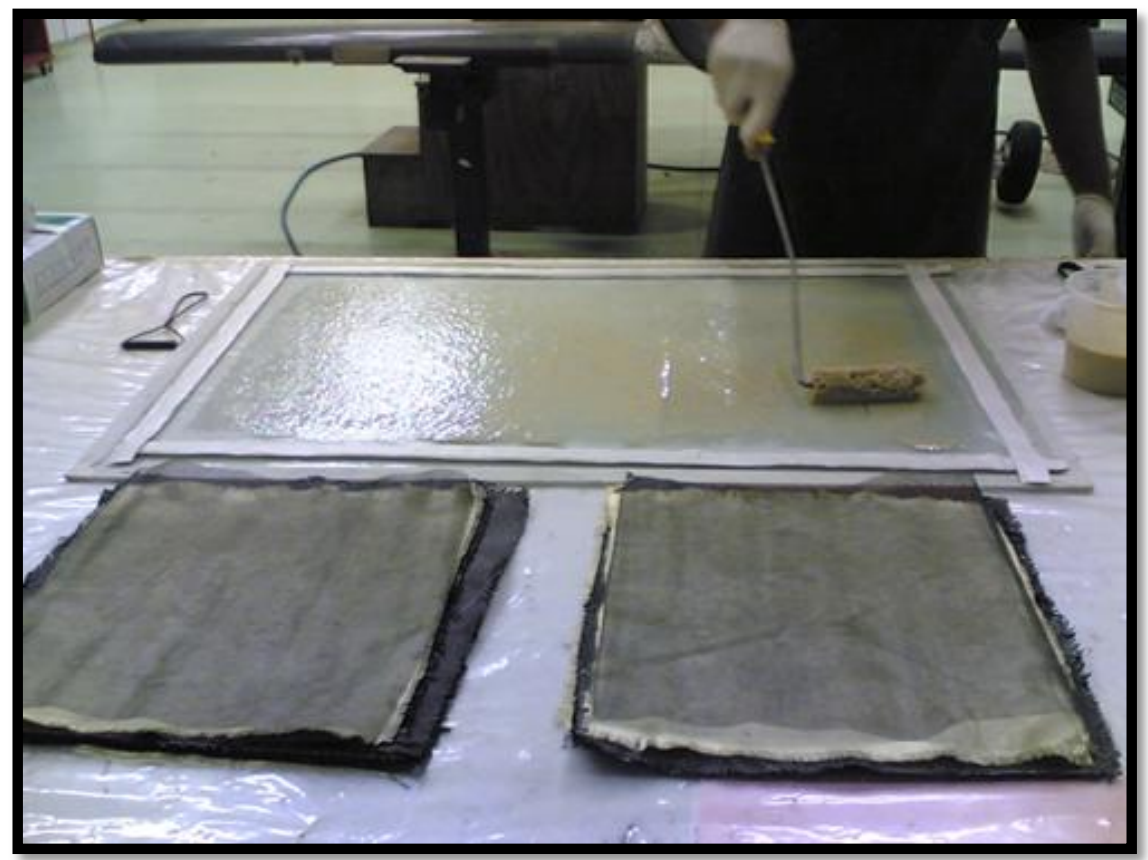

Figure 4. Resin distribution.

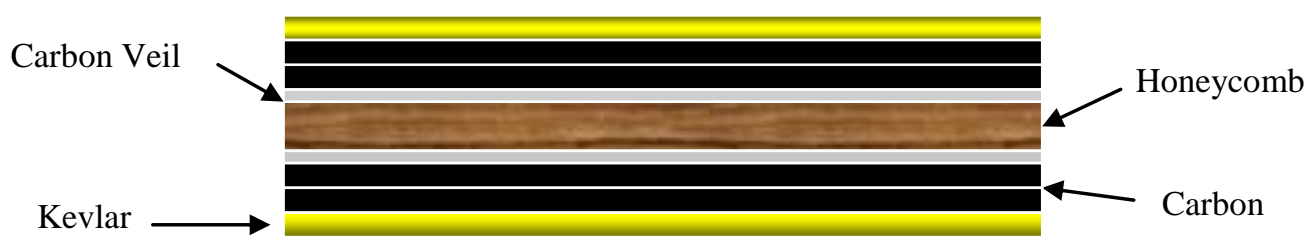

Figure 5. Geometry layout for the composite firewall.

\section{Velocity measurement}

The speed before the target and the final speed after the target were estimated by the speed camera recording the occurrence of the effect at 80,000 images per second with a picture size of $500 \times 36$ pixels for each picture. The speed camera recorded the first speed of the shot and final speed the penetration of the target. The particular Hotshot cameras are appeared in Figures (6). The Hotshot camera picture recording can be begun or ceased remotely through a handheld switch, an immediate sign from the subject or an outside trigger. Pictures can be immediately assessed and downloaded to a computer of the program for increasingly itemized examination or picture chronicling and capacity. The camera head imager must get enough light to see subtleties of the picture, and record the subject at the ideal size, so the noteworthy piece of the movement can be seen obviously. The camera is adequate for chronicle a particular occasion just as review proceeds with the video until an occasion triggers a conclusion to the succession. The passed account time relies upon the number of edges every second recorded and the number of edges that the memory can store. The camera records an occasion until the administrator gives a stop direction or a trigger created by an outside source stops the chronicle procedure. 


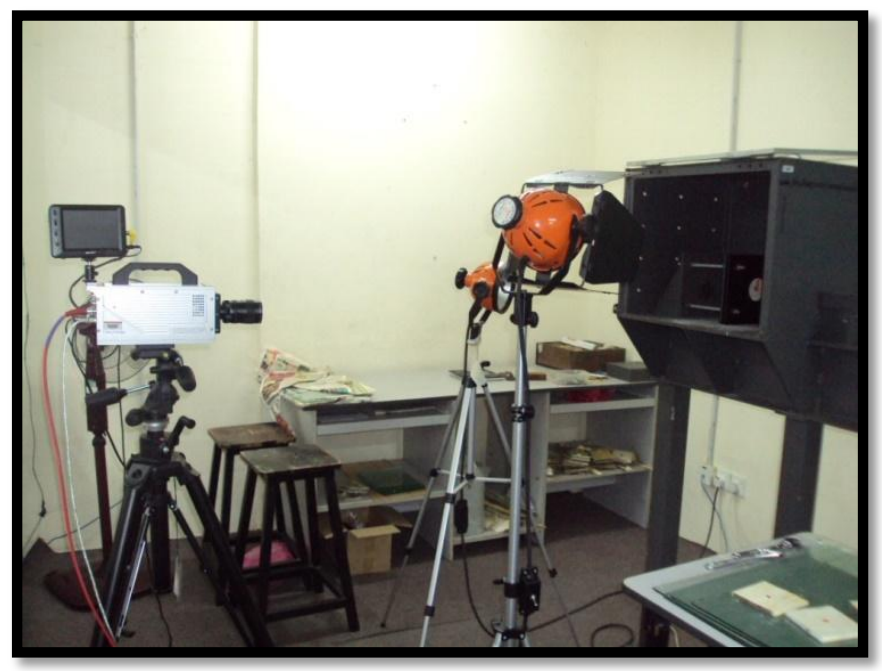

Figure 6. high-speed cameras to calculate the velocity bullet.

\section{Projectile}

Simulation bullets from steel are fabricated in the UPM workshop. The selected nose shape of bullets represents a critical issue of impact phenomena. Essentially, the chosen bullets depend on the most effective shapes. The flat cylindrical bullet has the same shank diameter of $8 \mathrm{~mm}$ and the same mass of 5 grams. The projectile simulation is illustrated in Figure (7).

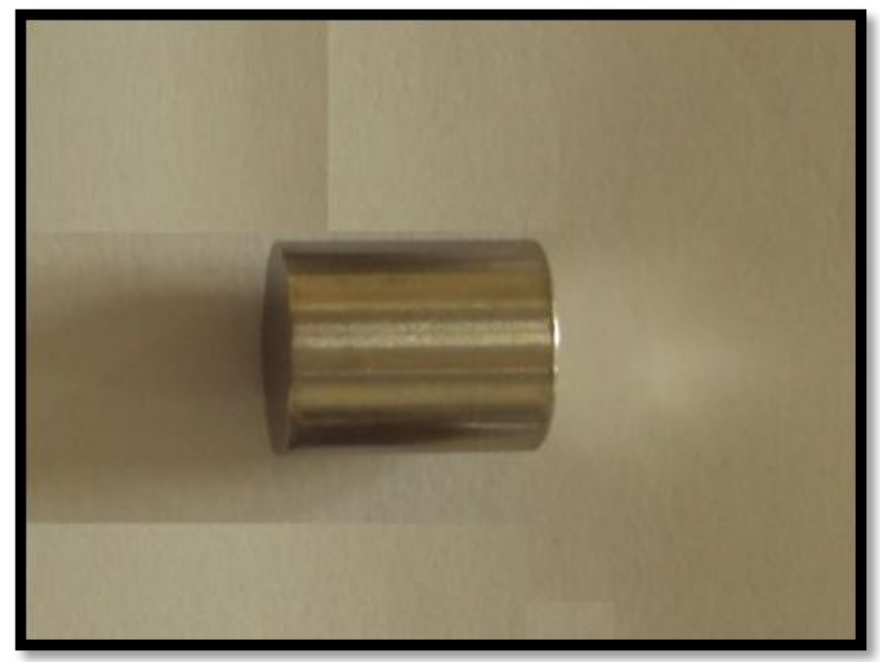

Figure 7 . The type of projectile: flat cylindrical.

\section{Results and discussions}

\section{Tensile and compression tests of the composite (mechanical properties testing):}

Composites material has layer properties, for example, quality, stiffness, thermal and dampness conductivity, wear and natural obstruction which unequivocally rely upon the type of support in the cover. So, the choice of composite material for making lightweight is the Kevlar and carbon fiber because they are the woven fabric type composite with honeycomb aluminum, where the fiber tows are large bundles of fibers are woven in two or more directions and high-performance materials. In table 1 given mechanical properties for composite materials. The tensile tests have been applied for composite material made from (Honeycomb aluminum, Kevlar29 and Carbon fibers) were done at room temperature. The tensile test result has been 
calculated for composite materials; from these results the modulus of elasticity, tensile yield stress, and ultimate tensile strength are shown in Table 1. The compression testing is one of the most used methods for determining the modulus of elasticity and compression yield stress of material. The stress-strain result has been plotted for composite materials from these data the modulus of elasticity, compression yield stress strength is shown in Table 1.

Table1. The measured mechanical properties for Kevlar29+Honeycomb Aluminium+ Carbon fibers (KHC).

\begin{tabular}{|c|c|c|c|c|c|}
\hline \multirow{2}{*}{ Composite material } & \multirow{2}{*}{$\begin{array}{c}\text { Thickness } \\
\text { (in) }\end{array}$} & \multicolumn{2}{|c|}{ Tensile } & \multicolumn{2}{c|}{ Compression } \\
\cline { 3 - 6 } & & $\boldsymbol{\sigma}_{\mathbf{y}}(\mathbf{M P a})$ & $\mathbf{E}(\mathbf{G P a})$ & $\boldsymbol{\sigma}_{\mathbf{y}}(\mathbf{M P a})$ & $\mathbf{E}(\mathbf{G P a})$ \\
\hline$(\mathrm{KHC}) 1$ & 0.42 & 34.2 & 70.5 & 52 & 76.8 \\
\hline$(\mathrm{KHC}) 2$ & 0.45 & 41.6 & 78.4 & 57.5 & 81.2 \\
\hline$(\mathrm{KHC}) 3$ & 0.5 & 53.9 & 82.8 & 60.7 & 91.4 \\
\hline$(\mathrm{KHC}) 4$ & 0.55 & 60.2 & 94.5 & 69.6 & 98.7 \\
\hline
\end{tabular}

\section{High-velocity impact}

The total work done for this study can be expressed as Abu Talib et. al [10]:

$$
\begin{aligned}
& W_{T}=\frac{3 \pi \sigma_{y}^{2} h R^{2}}{(-c+2 b+2 a)}\left(1-v_{21} v_{12}\right)\left(\frac{d_{2}}{d_{2}+2}\right)+\frac{\pi w_{0} e^{-r}}{6\left(1-v_{21} v_{12}\right)}\left[\begin{array}{l}
E_{2}\left(-r-1+v_{21}\right)\left(3 h^{2}+h^{3}\right)+ \\
E_{1}\left(1-v_{12} r-v_{12}\right)\left(3 h^{2}+h^{3}\right)
\end{array}\right] \\
& \frac{1}{2} m v_{b}^{2}=\frac{3 \pi \sigma_{y}^{2} h R^{2}}{(-c+2 b+2 a)}\left(1-v_{21} v_{12}\right)\left(\frac{d_{2}}{d_{2}+2}\right)+\frac{\pi w_{0} e^{-r}}{6\left(1-v_{21} v_{12}\right)}\left[\begin{array}{l}
E_{2}\left(-r-1+v_{21}\right)\left(3 h^{2}+h^{3}\right)+ \\
E_{1}\left(1-v_{12} r-v_{12}\right)\left(3 h^{2}+h^{3}\right)
\end{array}\right]
\end{aligned}
$$

The ballistic limit equation of the target functions of its (Honeycomb aluminum, Kevlar29 and Carbon fibers) properties can be expressed as Abu Talib et. al [10]:

$$
v_{b}=\sqrt{\frac{2}{m}\left(\frac{3 \pi \sigma_{y}^{2} h R^{2}}{(-c+2 b+2 a)}\left(1-v_{21} v_{12}\right)\left(\frac{d_{2}}{d_{2}+2}\right)+\frac{\pi w_{0} e^{-r}}{6\left(1-v_{21} v_{12}\right)}\left[\begin{array}{l}
E_{2}\left(-r-1+v_{21}\right)\left(3 h^{2}+h^{3}\right)+ \\
E_{1}\left(1-v_{12} r-v_{12}\right)\left(3 h^{2}+h^{3}\right)
\end{array}\right]\right)}
$$

The statistical correlation of total work and ballistic velocity with experimental results as shown in table 2 .

The influence measured for these experiments is the effect of the final velocity on the original speed. show that plotted the final velocity increased as the initial velocity increase for composite material (Honeycomb aluminum, Kevlar29 and Carbon fibers) target of different thickness 0.42 in, 0.45 in, 0.5 in and 0.55 in as shown in figures $(12-15)$. The Recht and Ipson [11] empirical equation compared with relation initial velocity and final velocity it's the plotted a good agreement and percentage error is $3.4 \%$. The ballistic velocity and initial velocity as follows: $V_{r}=\sqrt{V_{i}^{2}-V_{b}^{2}}$, where $\mathrm{Vr}$ is the final velocity, $\mathrm{Vb}$ is the ballistic velocity and $\mathrm{Vi}$ is the incident velocity. The figure (8) and figure (9) show a photo of the (Kevlar29, Honeycomb aluminum and Carbon) fibers target through the impact of flat cylinder bullet for different layers. The experimental ballistic velocity for composite material of different thickness ability of target on absorption the energy through high-velocity impact undergoing bullet flat cylinder, the kinetic energy results increased 
with initial velocity increase, so the energy absorbed is supported on the different thickness for composite material and the experimental result compared with theoretical model show that result plotted a good agreement as shown in figure (10). The ballistic limit velocity for this material (Honeycomb aluminum, Kevlar29 and Carbon fibers) is dependent of the different thickness and the ballistic velocity plotted increased with different thickness so the experimental data compared with equation (3) of theoretical results Abu Talib et. al [10] a good agreement is obtained as shown in figure (11).

Table 2. The experimental results with the theoretical model Abu Talib et. al [10] for ballistic limit velocity.

\begin{tabular}{|c|c|c|c|c|c|}
\hline $\begin{array}{c}\text { Composite } \\
\text { Materials }\end{array}$ & $\begin{array}{c}\text { Thickness } \\
\text { (in) }\end{array}$ & $\begin{array}{c}\text { Ballistic velocity } \\
\text { Experimentally } \\
(\mathbf{m} / \mathbf{s})\end{array}$ & $\begin{array}{c}\text { Ballistic } \\
\text { velocity } \\
\text { Theoretically } \\
(\mathbf{m} / \mathbf{s})\end{array}$ & $\begin{array}{c}\text { Energy } \\
\text { Experimental } \\
(\mathbf{J})\end{array}$ & $\begin{array}{c}\text { Energy } \\
\text { Theoretical } \\
(\mathbf{J})\end{array}$ \\
\hline$(\mathrm{KHC}) 1$ & 0.42 & 191 & 197 & 0.9025 & 1.0769 \\
\hline$(\mathrm{KHC}) 2$ & 0.45 & 225 & 228 & 3.0625 & 3.49 \\
\hline$(\mathrm{KHC}) 3$ & 0.5 & 270 & 273 & 7.0225 & 6.3 \\
\hline$(\mathrm{KHC}) 4$ & 0.55 & 298 & 302 & 13.6025 & 12.96 \\
\hline
\end{tabular}

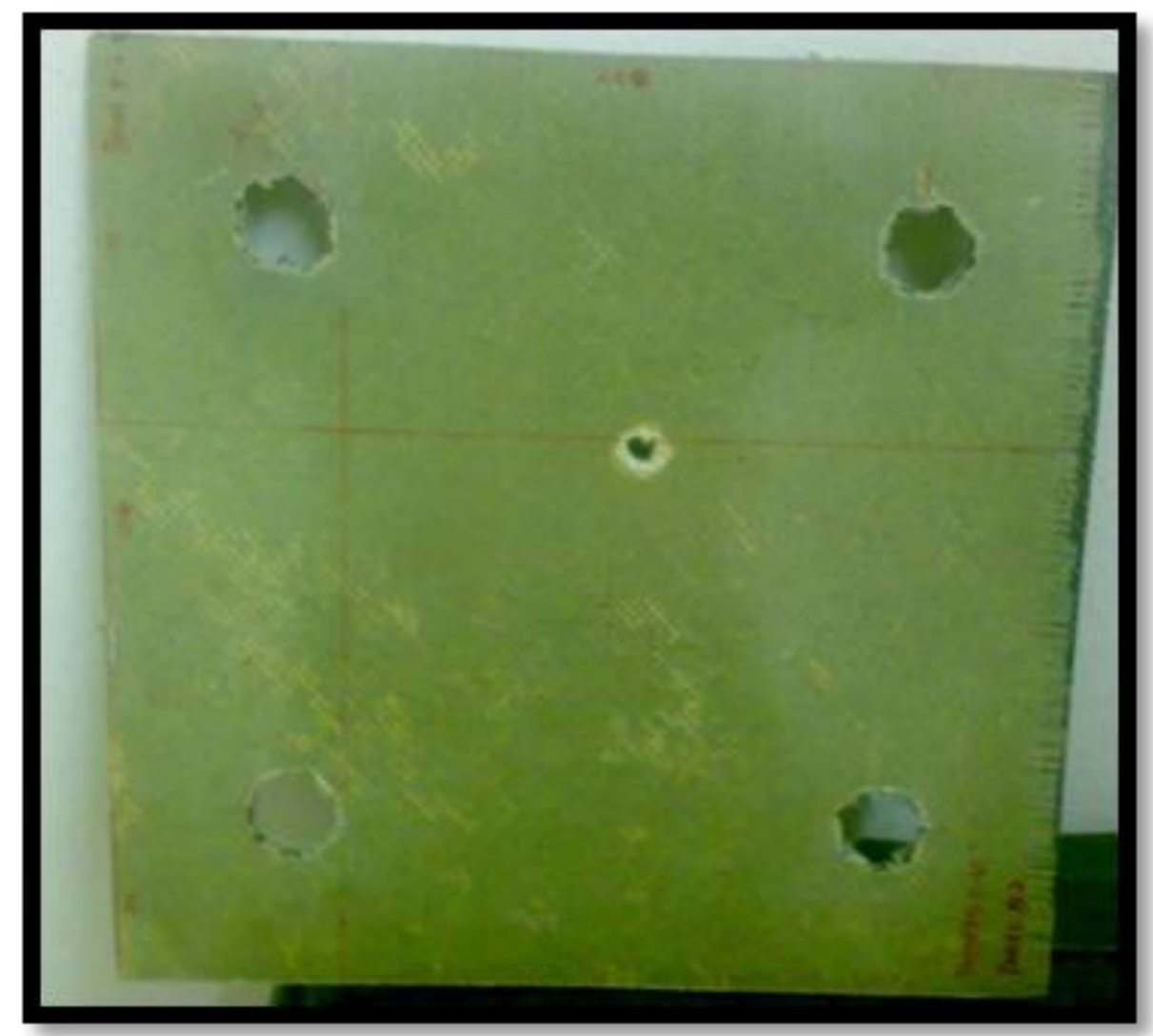

Figure 8. The composite material target of 14 layers woven Honeycomb aluminum, Kevlar29 and Carbon fibers struck by a flat cylinder projectile as $\mathrm{Vi}=270 \mathrm{~m} / \mathrm{s}$. 


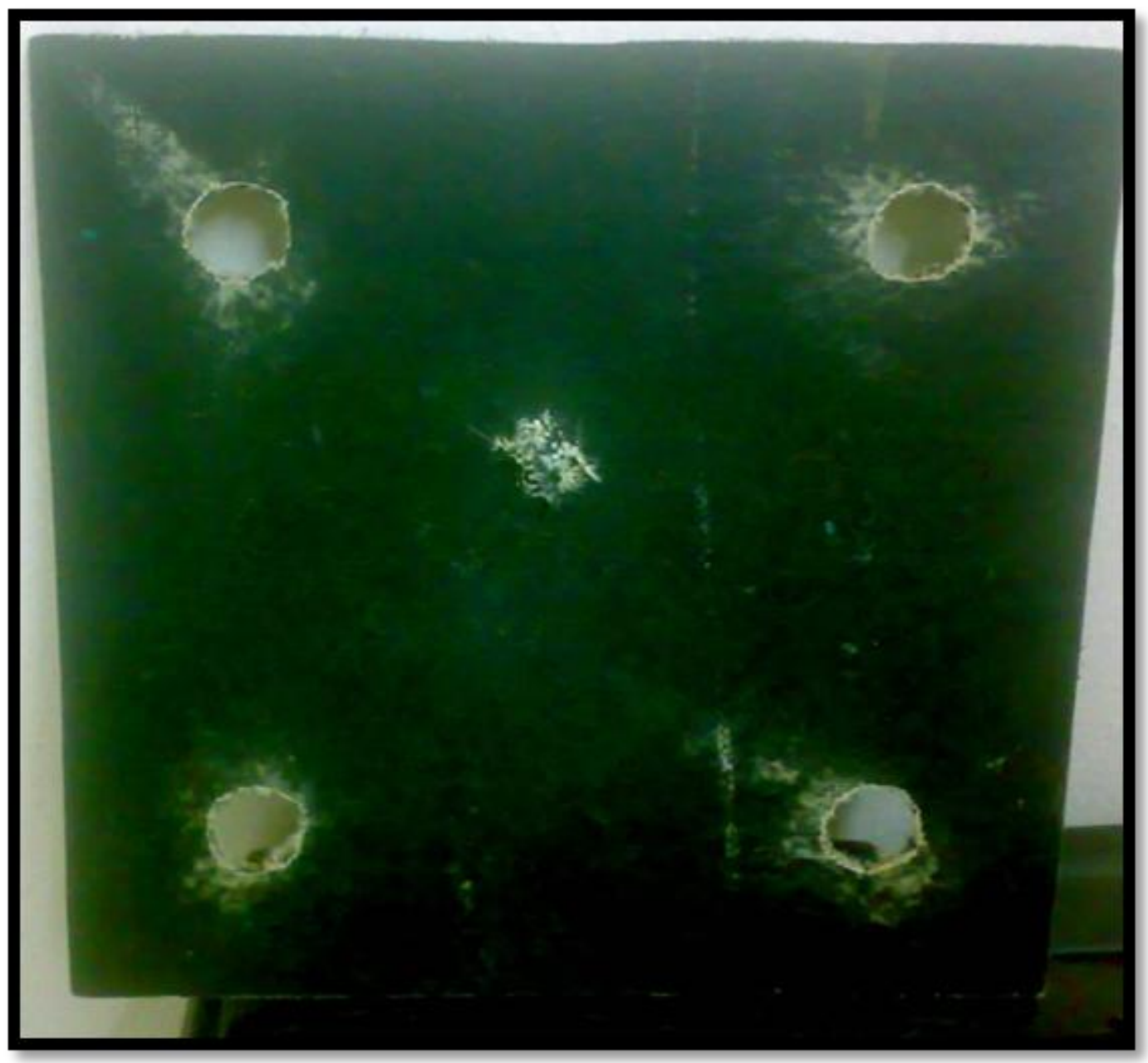

Figure 9. The composite material target of 20 layers woven Honeycomb aluminum, Kevlar29 and Carbon fibers struck by a flat cylinder projectile as $\mathrm{Vi}=270 \mathrm{~m} / \mathrm{s}$.

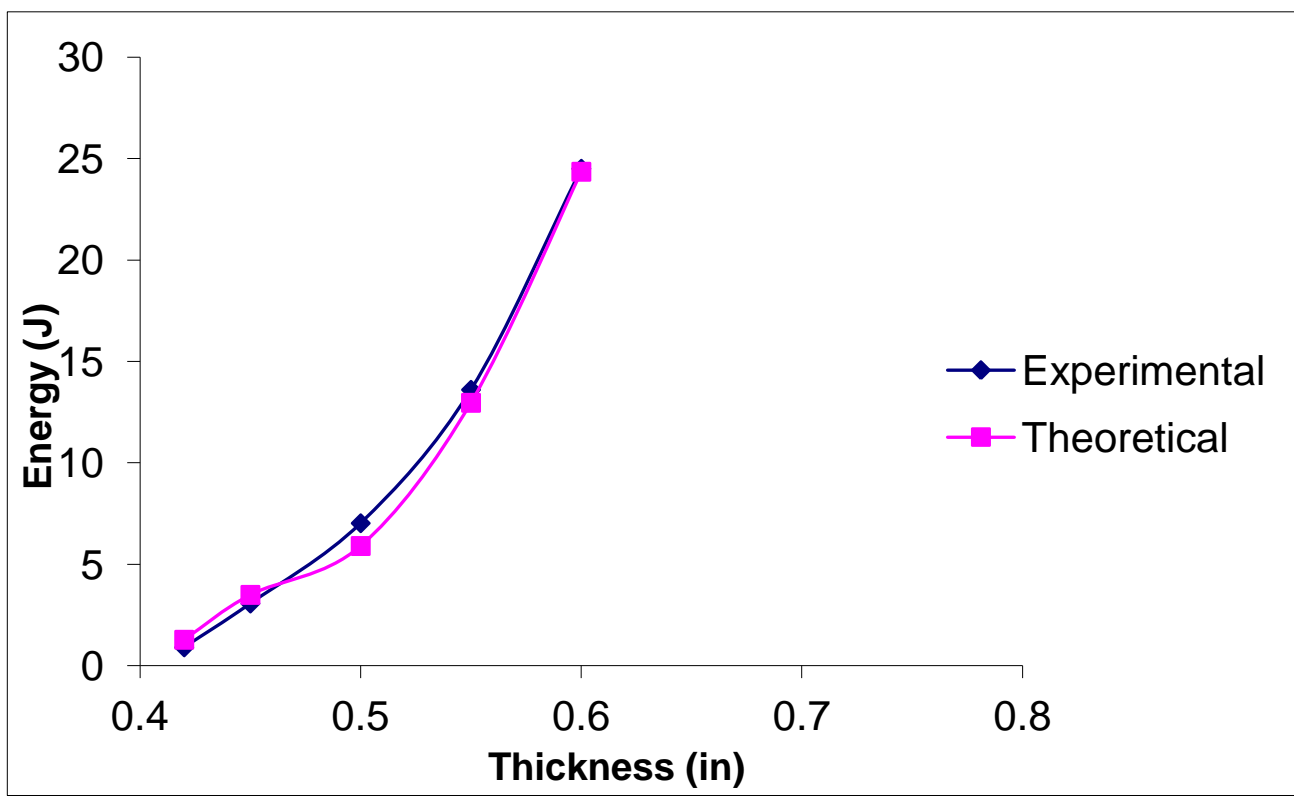

Figure 10. Full work is done on composite materials of the thickness of Honeycomb aluminum, Kevlar29 and Carbon fibers. 


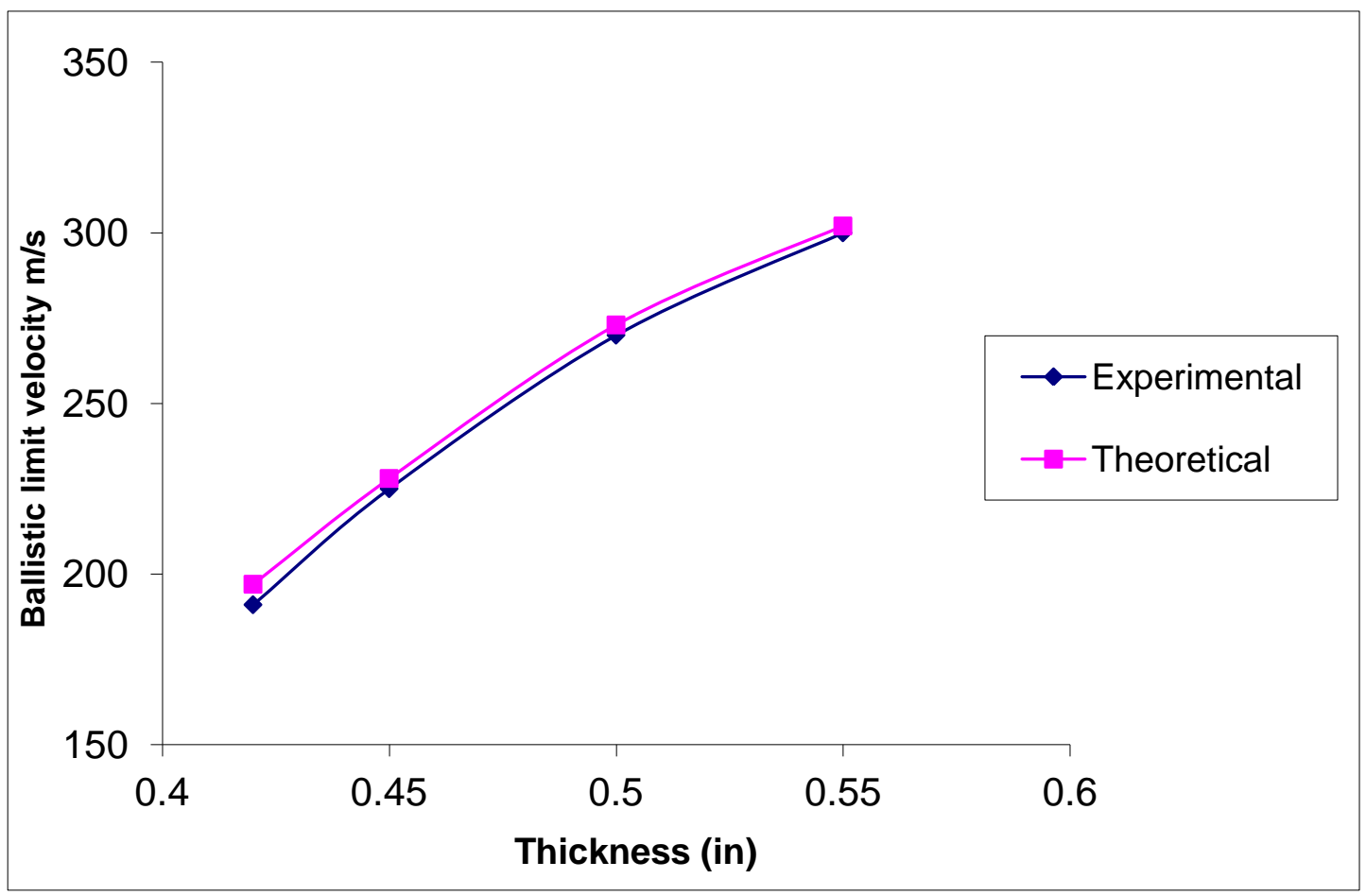

Figure 11. Experimental and Theoretical ballistic speed limits woven Honeycomb aluminum, Kevlar29 and Carbon fibers versus thickness.

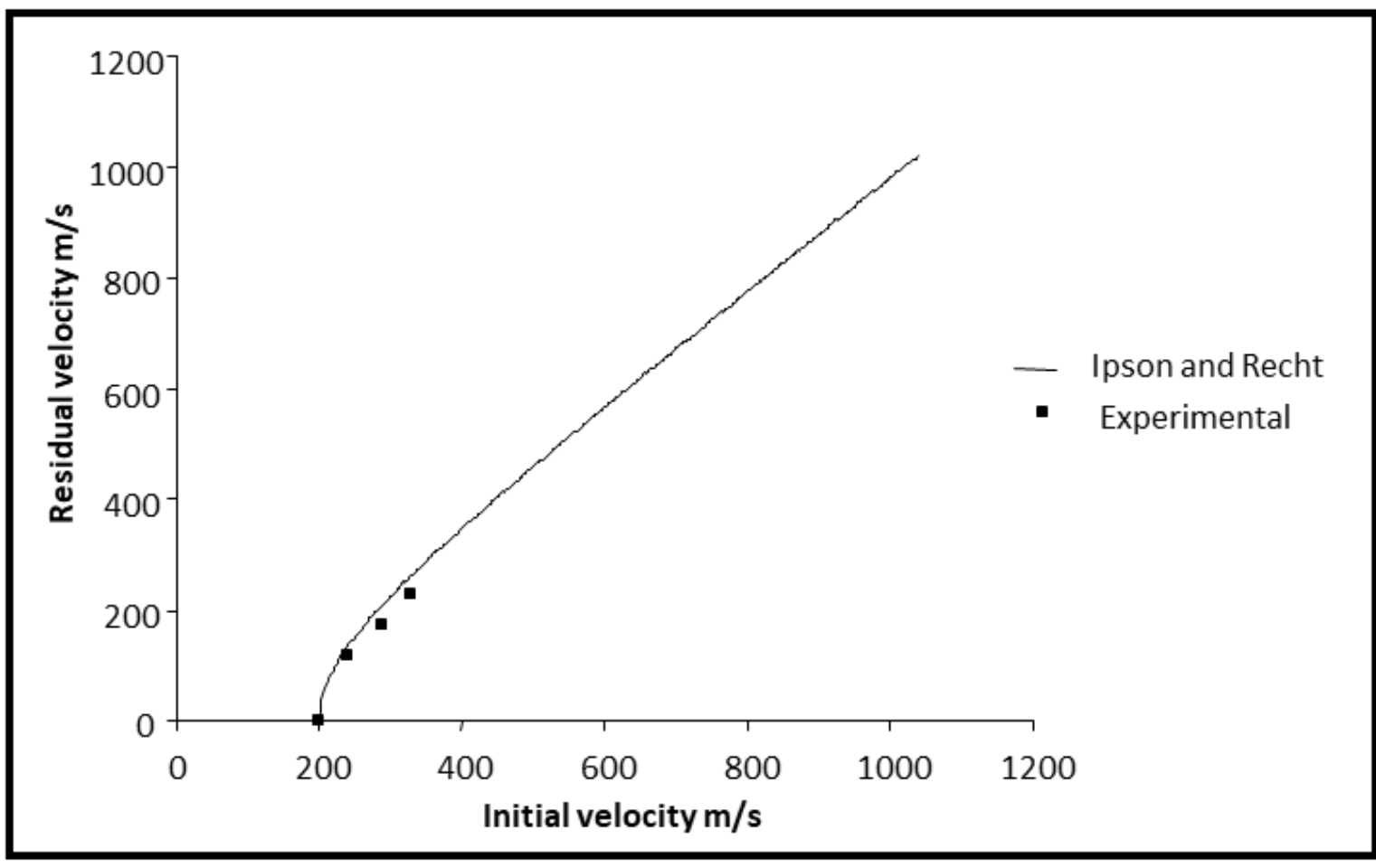

Figure 12. Residual velocity V(r) against initial velocity V(i) for thickness 0.42 in composite material by the flat cylindrical projectile. 


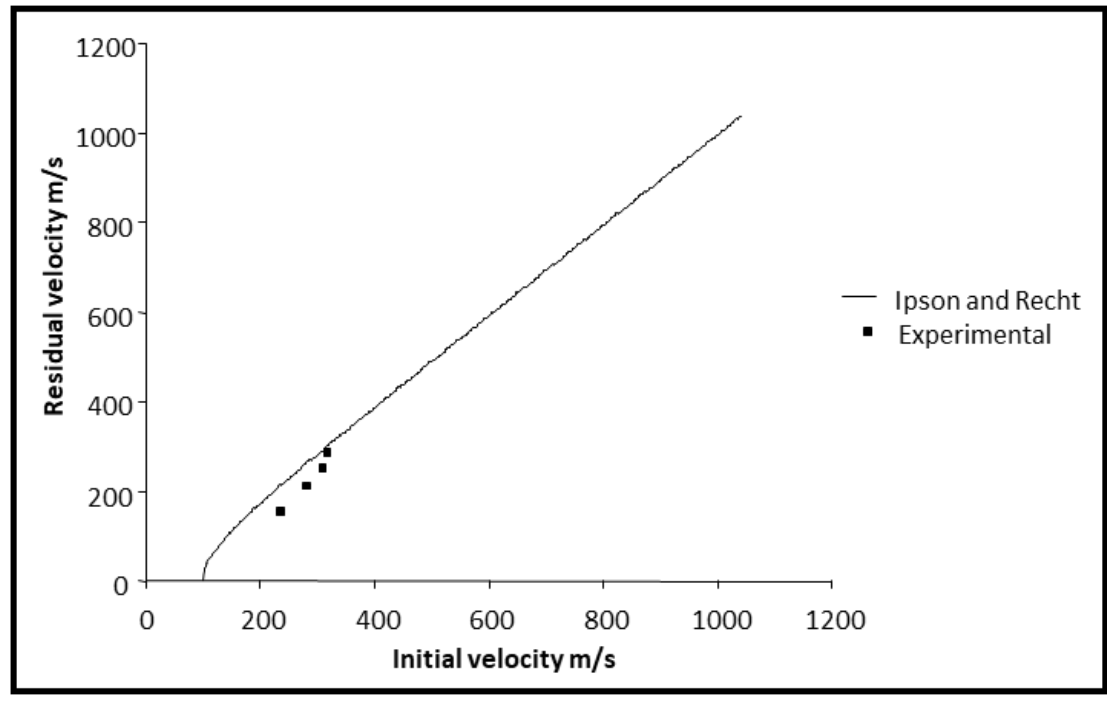

Figure 13. Residual velocity V(r) against initial velocity V(i) for thickness 0.45 in composite material by the flat cylindrical projectile.

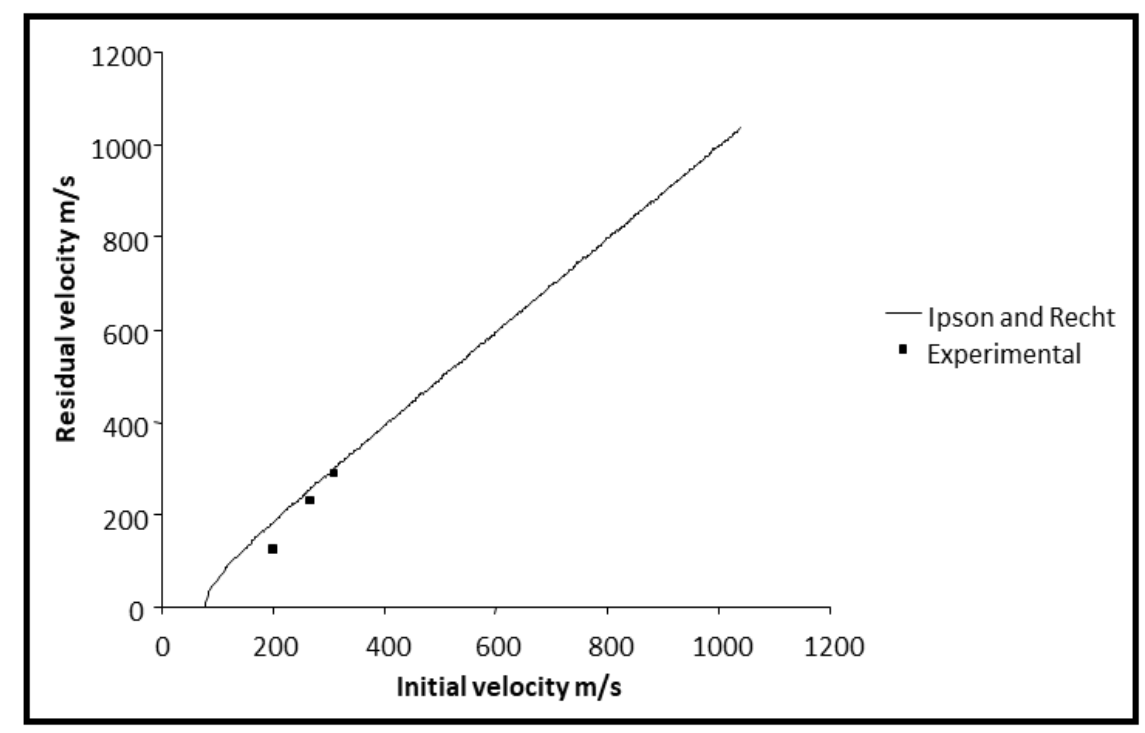

Figure 14. Residual velocity V(r) against initial velocity V(i) for thickness 0.5 in composite material by the flat cylindrical projectile.

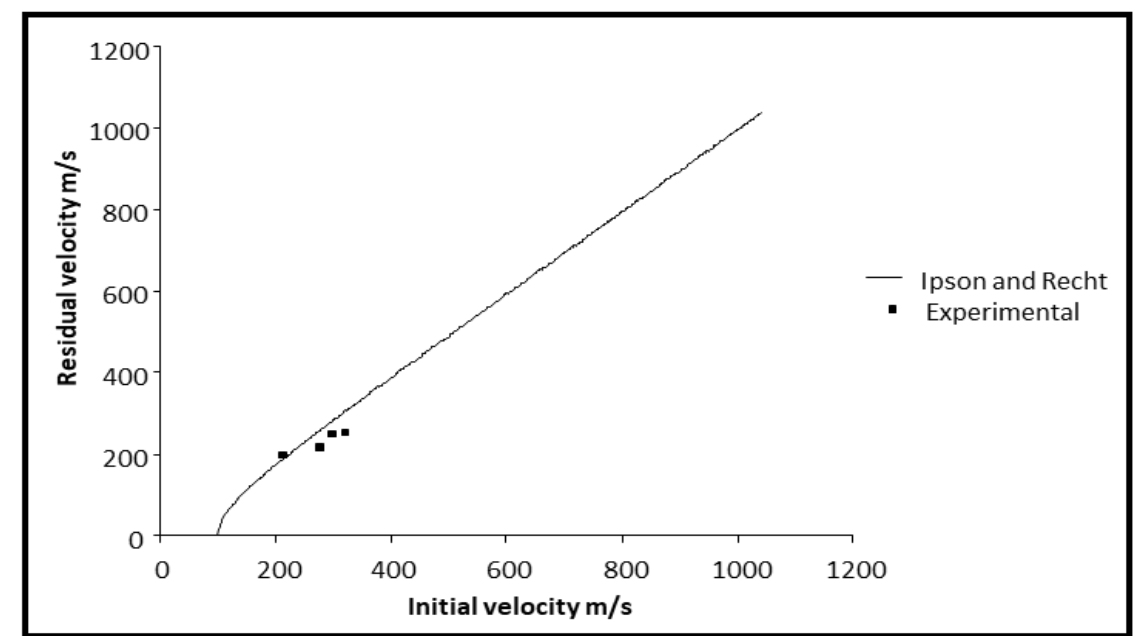

Figure 15. Residual velocity V(r) against initial velocity V(i) for thickness 0.55 in composite material by the flat cylindrical projectile. 


\section{Conclusions}

Form this work; it can be getting the following conclusions:

1. It was found this ballistic velocity experimental work composite material compared the behavior of the curve with energy and ballistic limit equation Abu Talib et. al [10].

2. The improvement in target thickness increases target ballistic quality.

3. The thickness of the targets extends the stored energy from the effect, so the aluminum Honeycomb tends to increase the reserved energy.

\section{References}

[1] A. Alavi Nia , S.B. Razavi , G.H. Majzoobi, "Ballistic limit determination of aluminum honeycombsExperimental study", Journal of Materials Science and Engineering A 488, p.p. 273-280, 2008.

[2] Essam Z. Fadhel, "Numerical Optimization of Sandwich Composite Structure under Flexural Load", the Iraqi Journal for Mechanical and Material Engineering, Vol.18, No. 4, p.p. 616-627, 2018.

[3] Essam Z. Fadhel, "Effect of the Elevated Temperature on Fatigue Behavior of Aluminum Alloy AA 7075", Journal of the University of Babylon for Engineering Sciences, Vol. 26, No. 8, p.p. 256-264, 2018.

[4] Enock A. Duodu, Jinan Gu, Wei Ding, Shixi Tang, "Performance of Composite Structures Subjected to High-Velocity Impact - Review", Global Journal of Researches in Engineering: A Mechanical and Mechanics Engineering, Vol. 16, Issue 4, Version 1.0, p.p. 54-64, 2016.

[5] L.H. Abbud, A.R. Abu Talib, F. Mustapha, A. Ali, "Ballistic Limit Behavior of Polymers Transparent Materials under High-Velocity Impact", International Journal of Engineering and Technology, Vol. 8, No.2, p.p. 61-66, 2011.

[6] Luay Hashem Abbud, " Experimental Determination of Ballistic Performance of Composite Material Kevlar 29 and Alumina Powder/Epoxy by Spherical Projectile", Journal of University of Babylon for Engineering Sciences Vol. 24, No. 4, p.p. 991-1004, 2016.

[7] Fawaz Abbas T. Najim, Hisham Tawfique, Luay Hashem Abbud, " Behavior Forms of Glass and Other Transparent Material Targets under High-Speed Impact Loading", Revista da Associação Portuguesa de Análise Experimental de Tensões, ISSN 1646-7078, Vol 14, p.p. 99-104, 2007.

[8] Nagendra, S., Hafka, R.T., and Gurdal, Z. (1992), "Stacking Sequence Optimization of Simply Supported Laminates with Stability and Strain Constrains" AIAA J. 30(8), 2132-2137.

[9] Guynn, E.G. \& O’Brien, T.K., "The Influence of Lay-up and Thickness on Composite Impact Damage and Compression Strength", AIAA Paper 85-0646, 1985.

[10] Abu Talib, A.R., L.H. Abbud, A. Ali, F. Mustapha, 2012, "Ballistic Impact performance of Kevlar29and Al2O3 powder/Epoxy Targets under High-Velocity Impact", Materials and Design; 35: 12-19.

[11] Recht R.F. and Ipson, T.W., 1963, "Ballistic Perforation Dynamics", Journal Applied Mechanics, 30 ,384- 390 .

[12] Thaier J. Ntayeesh, Mahmud Rasheed Ismail, Raed G. Saihood," Buckling analysis of reinforced composite plates with a multiwall carbon nanotube (MWCNT)" Periodicals of Engineering and Natural Sciences, Vol. 7, No. 3, pp.1275-1285, 2019.

[13] Hüseyin Uzun, Emrah Önal," Mechanical Properties and Corrosion Behaviors in 3.5\% NaCl Solution of Grade-A and Dual-Phase Steels Welded by FCAW", Periodicals of Engineering and Natural Sciences, Vol. 1 No. 2 pp.25-32, 2013.

[14] Noor Hadi Aysa," Evaluating of mechanical properties of (silicone/Arabic gum/fish hask) composites used as pressure garment prosthetics", Periodicals of Engineering and Natural Sciences, Vol. 7, No. 3, pp.1202-1208, 2019 
[15] Vitala H R, BP Dileep, A.Megalingam ,Karthik K,” Mechanical and Tribological Characterization Nitrided Al-7075/A12O3 Metal Matrix Composites", Periodicals of Engineering and Natural Sciences, Vol.6, No.2, pp. 64-70,2018.

[16] Ömer Yavuz Bozkurt, Özkan Özbek, Atban Rafea Abdo,” The Effects of Nanosilica on Charpy Impact Behavior of Glass/Epoxy Fiber Reinforced Composite Laminates", Periodicals of Engineering and Natural Sciences, Vol.5, No.3, pp. 322-327, 2017.

\section{BIBLIOGRAPHY OF AUTHORS}

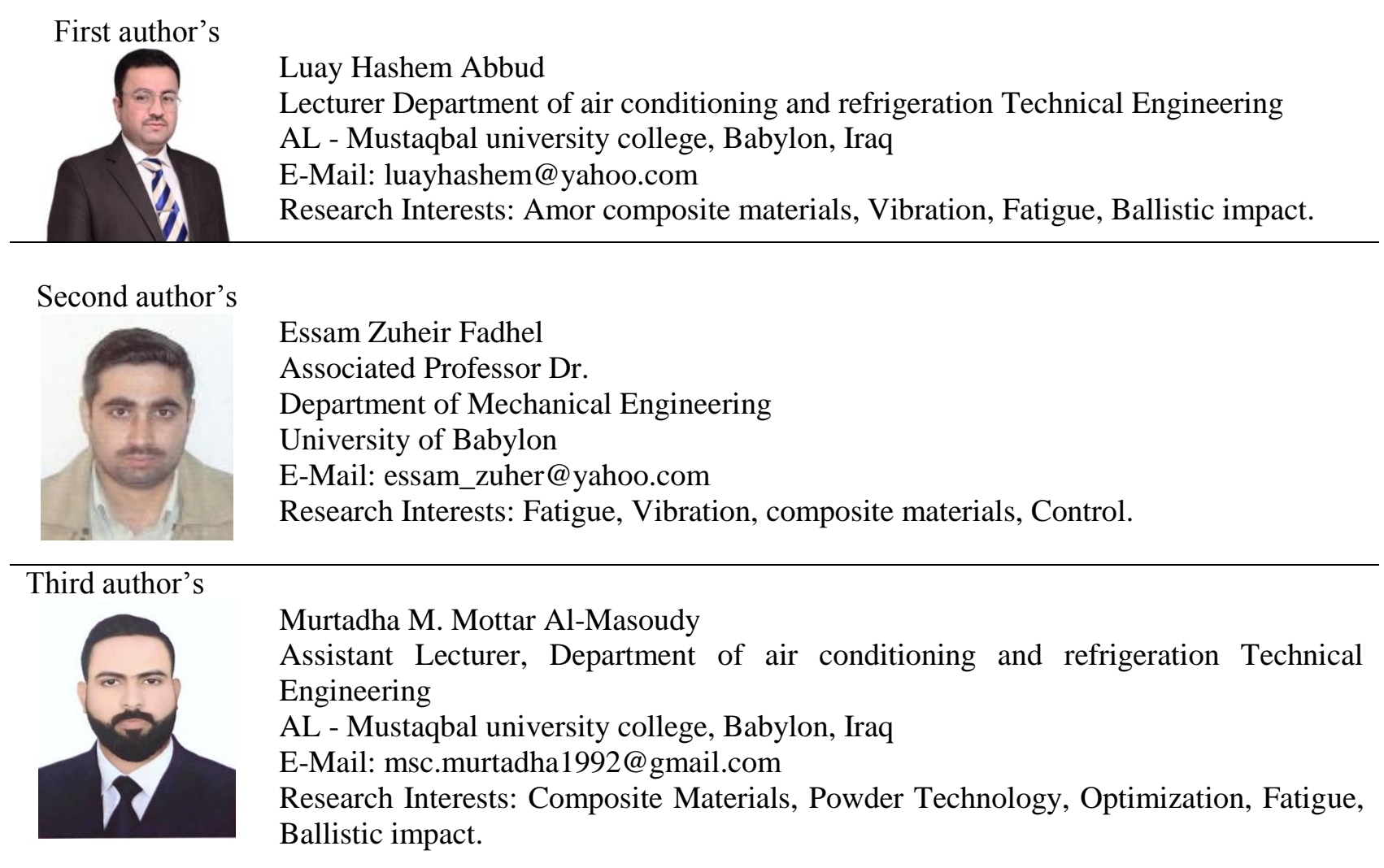

